\title{
Bridging Grammar and Communication: Focusing on the Preposition $O f$
}

\author{
Hirano, Junya - Matsumoto, Tomoko* \\ (Kumamoto University · Nagasaki International University)
}

Hirano, Junya \& Matsumoto, Tomoko. (2018). Bridging grammar and communication: Focusing on the preposition of. STEM Journal, 19(2), 21-45.

Focusing on the preposition of, this paper proposes a new method of grammar instruction to strengthen students' understanding of grammar rules, as well as their communication abilities. It is important for scholars and teachers to find a way to improve grammar teaching methods because they have not changed for several decades, while methodologies for improving students' communication skills have been discussed widely. Even ESL teachers who predominantly employ communication-centered teaching techniques rely on mechanistic methods to teach grammar, requiring students to memorize grammatical rules. The new grammar instruction method consists of two processes: understanding the essence of a particular rule and applying the understanding to a film dialog to see how grammatical rules are employed correctly in communicative settings. Understanding the essence of grammatical rules enables students to improve their communication skills and abilities; it also does not require them to memorize grammatical rules. Furthermore, film dialogs enable learners to understand the importance of context and setting in the process of communication. To demonstrate how this new method works, the paper explains the essential meaning of of as a part of a larger whole, and shows how the essential meaning is employed in film dialog.

\section{INTRODUCTION}

In ESL education, communication and grammar are taught using very different approaches. Typically, communication is taught through organic processes that encourage ESL learners to actively exchange information and ideas, whereas grammar is taught mechanistically —educators almost exclusively focus on rules and correctness (Nekoda, 2015). These distinct, and sometimes mutually exclusive, approaches only serve to widen

${ }^{*}$ First author: Hirano, Junya; Second author: Matsumoto, Tomoko 
the gap between grammar and communication. As discussed in-detail below, while methodologies designed to improve students' communication skills have been discussed widely, the methods of teaching grammar have received very little attention. Educators and learners seem to believe that communication skills can be developed even without a sound understanding of grammatical rules. The communication-centered approach alone is not sufficient to improve learners' English competency. Therefore, it is important to overhaul the mechanical and memorization-centered to grammar education.

As for Leki (1996), focusing on only one of these two aspects amounts to instructing learners to use only their left hands, but expecting them to suddenly use their right hands for certain tasks. For example, ESL learners in Japan are typically expected to learn about and understand auxiliary verbs solely by comprehending grammatical rules; educators typically do not focus on the complexities of communicative settings in this context. As a result, Japanese ESL learners rarely use auxiliary verbs such as would while communicating (Peterson, 2014). Their statements tend to be inaccurate, if not completely wrong. Mechanical grammar education mainly focuses on memorization, and it does not allow students to develop their communication skills. Overdependence on memorization results in the underdevelopment of one's communication skills. Effective grammar teaching, therefore, is not mechanical or overdependent on memorization; it enables learners to develop their English competency.

To avoid forcing learners to understand comprehend and memorize a large body of grammar rules and principles, teachers must discover the essence of target grammar rules, to minimize what Nation (2001) calls "the learning burden"(p. 25). A focus on the essence of a rule or principle lightens this burden. This essence can also serve as a foundation, enabling learners to adapt to different contexts and appreciating subtle differences in meaning. To help students improve their communication abilities, teachers should encourage them to explore how grammar is applied in authentic communication settings. Of course, there are many grammar rules that are difficult, but as this paper has only limited space, the authors restricted themselves to the preposition of alone. As will be seen below, the importance of prepositions is often underestimated.

Using one preposition, of, as an example, this paper aims to propose a new method of grammar instruction that can strengthen students' understanding of grammatical rules and their ability to communicate while avoiding making students memorize grammatical rules. Grammatical rules serve as a foundation, and enable learners to adapt to various contexts and appreciate subtle differences in meaning. To improve students' communication abilities, teachers should encourage students to understand grammatical rules and explore the ways in which grammar is applied in communication.

The new method incorporates two processes; understanding the essence of a particular rule and applying the understanding to film dialog to observe grammatical rules actually 
employed in a communication setting. To understand the essence of a grammatical rule or principle requires learners to do more than memorize rules, and it reduces "the learning burden." Furthermore, as discussed in-detail later, film dialog constitutes an effective text for the facilitation of understanding because it allows learners to understand the context and setting of the observed communication and because it also enhances students' capacity to apply grammatical rules correctly (Matsumoto, 2014). From this point of view, even simple dialog can be extremely interesting, encouraging students to explore complex grammatical principles.

In the remainder of the paper, the authors first describe how communication and grammar have become divorced in ESL learning in Japan, discussing this specific case as an example of the importance of grammar being overshadowed by communicationcentered ESL teaching styles. The third section shows the challenges that teaching grammar poses for both teachers and learners, focusing on a difficult grammatical subject that ESL students must master: prepositions. Selecting among these of as the main theme, the fourth section discusses its various meanings, by comparing it with other prepositions, to uncover its essential meaning and function, which it does not share with other prepositions. Last, by examining the different ways in which of is used in film dialog, the authors put forward a perspective accounting for how understanding the essential meaning and function of a preposition can improve students' communication skills.

\section{GRAMMAR TEACHING UNIMPROVED}

\section{Grammar vs. Communication: A Case in Japan}

The second section of this paper first provides a brief overview of ESL education in Japan to show how communication and grammar has failed to be married. By understanding how problematic the divorce between them is, the urgency of discovering new grammar instruction methodologies should become apparent.

In Japan, ESL educators typically prioritize grammar and grammatical principles over communicative aspects (Nakata, 2006). Verbal communication is not regarded as an important aspect of ESL education; in fact, it is often overlooked. Japan's approach to ESL education is often criticized for its excessive focus on memorization and examinations; it is also typically instructor-centric. Gitsaki (2005) and Seki (2008) note that most Japanese ESL students are accustomed to a teacher-centric approach; they also claim that students typically have no specific goals other than proceeding to the next stage of education. ESL learners are expected to obey teachers' instructions (Nakata, 2006), and this is often regarded as the best way to gain admission to prestigious high schools and universities. In 
other words, ESL education in Japan is teacher-centric because this approach "is thought to pay off in terms of future career or social status" (Nakata, 2006, p. 155). Naturally, this approach has a negative influence on Japanese ESL learners. As Murasato and Orita (2008), Nakata (1999), and Ueda (2011) show, grammar-based learning demotivates learners, leading them to believe that English is a boring subject. In other words, learners are not motivated to communicate with others in English.

The revised curriculum guidelines released by the Ministry of Education, Culture, Sports, Science and Technology (MEXT) in 2008 clearly suggests that grammar should be taught in relation to communication skills. That is, grammar must be taught to enable learners to develop their communication abilities and skills. In fact, it can be argued that the primary purpose of language education is to enable the development of learners' communication abilities. In addition, Kimura and Wakasugi (2014) and Shirono (2014) point out that ESL learners are more motivated to learn English when they are taught using activities aimed at developing their communication skills. There have been numerous studies and reports on communicative instruction, and some have contributed to the development of innovative teaching materials, which have in turn encouraged and motivated ESL learners. Online fantasy sport games (Silsbee, 2016), manga books (Howell, 2014), and mobile games (Ban \& Minagawa, 2013) have been found to be effective materials to motivate ESL learners. However, some have criticized the increasingly popular communication-centric approach to English education. For instance, Nekoda (2015) argues that communication-centered English education tends to downplay the importance of grammar and vocabulary. Nakahara and Nakagawa (2010) suggest that this approach does not enable learners to develop a proper understanding of the English language. Although it is important to focus on communicative activities, it is equally important to enable ESL learners to develop a good understanding of English grammar. This is important to ensure that learners learn from lexical and grammatical errors, as well as to reduce their dependence on idiomatic expressions.

The efforts aimed at bringing about a paradigm shift in English education have focused especially on communication, and the importance of grammar seems to be underestimated. A significant number of researchers and teachers have been developing communicationcentered teaching methods. However, as Onishi (2014) notes, the methods used to teach grammar have not changed in a long time, and teachers have been using old, ineffective methods to teach grammar. Similarly, while methodologies for improving students' communication skills have been discussed widely, methods of teaching grammar have generated little interest among scholars. It is rather surprising that not enough methods have been developed to teach grammar in an effective manner. As a result, teachers who predominantly employ the communication-centered approach rely on old, unimproved, and mechanistic ways to explain grammatical rules. These methods merely require 
students to memorize grammatical rules and principles. Therefore, in order to improve students' communication skills, it is important to develop more effective methods of teaching grammar.

\section{A Problem Ensues: Of Course, Sure, and Of}

In the course of an investigation of communicative language teaching (CLT) in South Korea, $\mathrm{Li}$ (2001) notes that it is a common misconception among instructors that CLT requires the exclusion of grammar instruction. Li stresses that teaching grammar must support students as they learn a language. In short, learning grammar is a means, and the mastery of the language is the end. This idea is quite similar to the official policy of the Japanese MEXT. However, the instruction of grammar has not yet been successful as a means to that goal.

For example, when learning a common expression such as of course, students as well as teachers would simply memorize the meaning of of course without having grammatical understanding on the preposition of. If learners do not have clear grammatical understandings on the expression, it means that their communications skills are built upon a shaky ground, which would cause problems as followings.

Of course is well known as a very commonly used adverb in everyday conversation, and ESL learners typically have little trouble understanding it in relation to words or phrases in their native languages. Moreover, most ESL learners understand that sure and of course are used almost identically: typically, they are both used to politely express permission, agreement, or compliance. However, both these expressions are used in various contexts where one or the other may be inappropriate, and this may confuse some ESL learners and teachers. Although the two are generally used interchangeably, their meanings have a difference of nuance. This subtle, but clear, difference must be foregrounded if the two expressions are to be used properly in a communication setting. That is, without a clear grammatical understanding of the difference between of course and sure, learners will not be able to use them appropriately and authentically. Intriguing examples of the nuances of difference between them can be found in film dialog.

For instance, in the film About A Boy (Rosenthal, De Niro, Epstein, Bevan, \& Fellner, 2002), Will claims that he has a child (although he does not). Marcus does not believe him, and aims to expose Will.

MARCUS: You don't have a kid, do you?

WILL: What?

MARCUS: You don't have a kid, do you?

WILL: Of course, I've got a kid. What are you talking about? 
MARCUS: No, you don't. I've been watching you, and you don't have a kid.

(Conversation 1, About A Boy)

To counter Marcus' accusation, Will says, Of course, I've got a kid. In this context, it is particularly interesting to examine whether Will could have said Sure, I've got a kid. If so, would the meaning or the tenor of the sentence have changed? Or is it inappropriate to use sure in this context, and if so, why? How, moreover, should teachers address this question?

Of course, it is possible for teachers to explain the difference with reference to dictionaries. However, the mechanistic discussions provided there are often difficult for learners to understand in how they bear on authentic communication. For instance, according to the "Oxford Advanced Learner's Dictionary of Current English" (2015), of course is used to mean "what you are saying is not surprising or is generally known or accepted" (p. 352). Swan (2016) also provides a detailed discussion: (1) its use implies that the answer to a question is something everybody will agree with or know, (2) of course is used in response to a request, to convey the agreeable nature of a request, or to express one's willingness to address the request, and (3) it is appropriate to use of course in a situation only when the questioner can be expected to know that the answer is most likely affirmative. As for sure, The Cambridge Academic Content Dictionary ("Sure," n.d.-b) and the Collins English Dictionary ("Sure," n.d.-a) explain that it means certainly and is an informal way to say yes or all right, especially in response to common questions such as Do you know him? the Longman Dictionary of Contemporary English ("Of course," n.d.) characterizes the difference between of course and sure, as one of politeness. Of course is typically used to mean yes or to grant permission in a polite manner, and it is generally more polite than sure. However, of course may be considered impolite if it is used to respond to a rather obvious statement of fact, such as It is cold. This is mainly because the speaker is expressing a judgment that such a statement is rather self-evident.

These discussions are mechanistic and logical, and they do not help learners grasp how such expressions can be used communicatively and authentically. That is, learners have difficulty seeing how these expressions can be used in authentic communication or how they can be used to make a subtle yet clear distinction that depends on context.

Needless to say, these explanations do not sufficiently address whether or not it is appropriate for Will to say Sure, I've got a kid. In other words, questions such as this one cannot be addressed solely from the mechanistic or grammatical perspective. This is mainly because these perspectives do not enable one to focus closely on the experience of communication or contextual complexities. Therefore, teachers must clearly show the difference between these two words so that learners can use them authentically and appropriately. In other words, it is important to develop a new method of teaching 
grammar - that is, it is important to go beyond the old-fashioned and mechanistic methods of citing textbooks and dictionaries.

The differences between of course and sure can easily be grasped if grammar rules are taught together with communicative activities and strategies. If learners can understand the essence of of, they would be able to determine differences between expressions that they encounter themselves, applying the essence of the word of to understand of course. Before exploring how to teach the difference between of course and sure with a focus on the essence of $o f$, the paper examines the difficulties and challenges that orthodox ways of teaching prepositions, discussing that the development of new methods of grammar instruction is an urgent matter for teachers of English who wish to be effective.

\section{Challenges Involved in Teaching Prepositions}

Although the paper has chosen of as a core theme, there should be no inference that teaching of is a particular challenge. All common prepositions pose similar a challenge to teachers and learners. Not only are all prepositions considered to pose difficulty to teach and to learn, but learners are also often left alone to memorize their uses, one by one. This scenario can even deteriorate further: a teacher may view prepositions as less important than other grammar topics. This section discusses the challenges posed by the instruction of prepositions.

Teaching prepositions is one of the most challenging tasks in English education. Lorincz and Gorden (2012) note that teaching prepositions is particularly challenging because they are notoriously difficult to fully master, especially for ESL learners. Mastering prepositions is extremely difficult for three main reasons. First, there are approximately 60 prepositions in English. Second, prepositions are polysemous in nature, meaning that each preposition has multiple meanings. Third, prepositions are monosyllabic, which makes it difficult for ESL learners to recognize them in spoken communication. Moreover, the same prepositions often have different meanings in other languages, whereas some languages do not have prepositions at all. Zhen and Park (2003) have noted that Korean and Chinese ESL learners find it extremely difficult to understand prepositions; in fact, these learners rate prepositions as the second most difficult aspect of grammar, whereas verbs are regarded as the most difficult. Similarly, Japanese ESL teachers and learners also find it difficult to teach and learn about prepositions.

Moreover, the Japanese language does not equivalent words for English prepositions, such as at, in, and of. Japanese ESL learners, therefore, find it especially difficult to grasp the meaning of these words. However, they are very commonly used in English, and it is important for learners to understand their meanings. It is also worth mentioning that very few reports indicate improvements in learners' understanding of these words. 
Kamimoto (2006) argues that prepositions are not taught with care. He also argues that not enough attention has been paid to the process of learning prepositions. Mochizuki, Koga, Sano, Kano, and Okuma (2013) show that Japanese learners of English make a lot of errors while using prepositions. Furthermore, as Matsushita (2012) shows, Japanese learners of English tend to depend heavily upon memorization-centered learning techniques. As a result, they find it especially difficult to select appropriate prepositions for a given context. In particular, they find it especially difficult to use at and in correctly. Japanese learners of English tend to pay little attention to the differences between these words; they typically translate these words into Japanese with the suffix -de. Furthermore, prepositions are not taught holistically, and educators have not developed effective teaching methods and materials (Kotani, 2003). Therefore, as Fuyuno (2013) found, learners tend to use prepositions in a one-size-fits-all manner.

Phrasal verbs, consisting of prepositions and verbs, are also known to be notoriously difficult for learners of English; they are syntactically and semantically complex. In general, learners are only expected to memorize phrasal verbs even though they are used frequently in everyday conversations. As Matsumoto (2014) argues, it is important to develop a good understanding of phrasal verbs to improve one's communication skills. Horiike (2003) shows that learners tend to think that phrasal verbs such as put off have the same meaning as single verbs such as postpone. In general, learners pay little attention to the meanings of different prepositions or adverbs in phrasal verbs. Takeoka (2010) states that memorization-centered instruction makes it difficult for learners to grasp how words and phrases are actually used. It is necessary to pay attention to subtle changes in meaning and grammatical properties. Using mechanistic methods to explain grammatical principles prevents learners from grasping the essence of words. In short, it negatively affects their communication abilities.

\section{Erroneous Uses}

According to Swan (2016), the reason why learning prepositions is difficult for learners is that each preposition can have a number of different uses. The author finds that a certain well-known dictionary lists fifteen main functions for at, stating that teachers tend to require their learners to simply memorize all of them. There is no denying that listing the main functions of each preposition would help some learners, but it is beyond confusing, amounting to a huge burden, for most learners, because they must discern the exact way in which each function of a given preposition varies from the others. As shown below, learners tend to misuse prepositions when they have not mastered the differences among them. 
Egawa (1981) narrows down the list of functions of of allowing learners to grasp its essential functions. He divides those functions into the following five categories: separation, part-whole relation, modifier, theme, and time. Egawa divides the function of separation into four further uses: location, origin, removal, and cause. Similarly, other prepositions, such as on, in, and at, have their own varied usages, and Egawa addresses them with examples. Most discussions of prepositions and their uses hitherto are organized systematically. The inherently complex nature of a preposition seems to require mechanistic explanations as the only effective way to help learners understand it. As noted above, ESL learners typically simply memorize the different uses of prepositions. Unsurprisingly, they often misuse them as a result (Matsushita, 2012). Even if their complex explanations are memorized correctly, learners nevertheless find it difficult to use them properly.

The followings are taken from the "Online Dictionary of Misused English" (n.d.) based on Japanese university students' corpus. These erroneous uses of prepositions show that learners simply relate prepositions to places or reasons.

(1) Japan met with defeat in the Pacific War, and Japanese people were forced to join the democratic countries $i n \rightarrow o f$ the world.

(2) She accused the man for $\rightarrow$ of stealing.

The prepositions in and for have been incorrectly used in these examples. In fact, the correct preposition for these sentences is of. However, it is only natural for learners to commit grammatical errors if they aim to understand prepositions by merely learning the rules. Therefore, it is necessary to overhaul the old, unimproved, and mechanistic ways of explaining grammar. Learners may tend to use in in (1) and for in (2) because they typically use in with spaces or places, whereas they mainly use for in statements of reason. It is impossible to avoid these errors if educators predominantly use memorizationcentered methods for teaching grammar.

Given the insistence on the memorization of the meanings of prepositions, learners comprehend grammatical rules without really understanding a given communication setting. Teachers should encourage students by explaining why sentences (1) and (2) contain grammatical errors.

Each preposition has its own unique, distinctive functions, and it is reasonable to assume why learners find it hard to understand prepositions. Interestingly, focusing on the similarities between prepositions tends to make it more difficult for learners to understand them. Grammar texts often explain prepositions by categorizing them as locators of space, directions, and other similar qualities. Prepositions such as at, above, in, and on are typically used as locators of space; some of these prepositions also function as locators of 
time. Learners often misuse prepositions because they cannot understand when and why a certain preposition is called for. Simply put, focusing on the similarities between prepositions only serves to confuse learners. Learners must grasp the differences between the prepositions.

Several scholars have suggested alternate ways of teaching prepositions to tackle this problem. Most of these suggestions involve the use of core spatial images associated with prepositions. However, they do not involve detailed explanations of grammatical rules and principles. For example, Fujimori and Yoshimura (2013) use digital teaching materials, including images, to teach English vocabulary and grammar. However, this kind of method is also quite ineffective, as it only enables learners to form vague ideas about a given preposition. In other words, it does not much help learners in actual communication settings.

Two main challenges confront the teacher in the instruction of prepositions. First, because of the nature of these words, their main functions must be compiled into long lists, and these only confuse learners: many of the functions of each preposition appear to be similar to other functions. This results in an inability to differentiate one from the others, and the prepositions are often misused. Second, the above-mentioned studies of prepositions mainly concentrate on techniques to strengthen learners' grammatical understanding, failing to relate that with communication competencies. Thus, it is important to explore methods of teaching prepositions that not only strengthen learners' grammatical understanding but support their communication skills and abilities.

\section{OF AND OTHER PREPOSITIONS}

\section{The Essence of Of}

Onishi and McVay (2006) and Tanaka, Sato, and Abe (2006) adopt a rather interesting approach for teaching grammar. They suggest that the very essence of a grammatical rule must be located; this essence must be taught to learners, and the learners must be supported as they develop their understanding and communication abilities. As an alternative to systematic and mechanistic explanations of grammar, in this method, teachers focus on the very core upon which learners can build their communicative abilities.

Several studies have sought to describe the essence of of. Although they do list the main uses of $o f$, they do not provide a description of the very essence of $o f$. For instance, Eto (2015) suggests that the functions of of can be divided into six categories: separation, material, possession, theme, origin, and affiliation. Interestingly, Eto also argues that these 
six categories can be further reduced to two larger categories: affiliation and separation. For example, affiliation and separation are expressed in (3) and (4), respectively.

(3) I was informed of the upcoming event.

(4) She was robbed of her watch.

Affiliation and separation are contradictory notions, but they share a common element: being within a realm. In (3), information about the upcoming event is affiliated to $I$ through being informed. In other words, the information is the knowledge that $I$ possesses about the event. As for (4), a watch is separated from she. To be separated from she, the watch had to have been in she's possession to begin with. It is not a watch that was stolen; it is her watch. Her watch was in her possession. However, the essence of of as within a realm is not entirely accurate. It lacks a sense of casual relation.

As for Kondo (1984), the sense of causal relation is an important aspect of the essence of of. Citing the OED, Kondo suggests that of originally meant the origin or point of departure. Yet, this too cannot be the essence of of. From also alludes to a cause, as in die of/from. Watanuki and Petersen (2006) argue that, although both of and from seem to allude to a cause, they indicate two totally different ideas. They argue that die of typically refers to a cause of death that is internal, such as a disease. Die from refers to death due to external causes as (6) below shows.

(5) He died of cancer.

(6) He died from the collision.

In (5), the cancer is part of he, eventually killing he. On the other hand, in (6), the collision is not part of $h e$, although it did cause the death of $h e$.

As Greenbaum and Quirk (1990) suggest, nouns generally have two cases: the genitive case and the common case. The former is also called the possessive case, and the possessive case can be paraphrased using of.

(7) There were strong objections from the island's inhabitants.

(8) There were strong objections from the inhabitants of the island.

(Greenbaum \& Quirk, 1990, p. 103)

The possessive case can be replaced by of because it is a function of of to show possession. A possession is a part of its possessor. In other words, of means the state of being a part. 
The protagonist of Anne of Green Gables, Anne Shirley, is an orphan, and she arrives at Green Gables from Nova Scotia to be adopted by siblings who run a farm. Anne is from Nova Scotia, and here, of course, from means origin. However, Anne is not part of Nova Scotia. Instead, Anne comes to be called Anne of Green Gables, not Anne from Green Gables. She is from Nova Scotia, but she is not Anne of Nova Scotia. The following sentence indicates the state of being part of a larger whole:

(9) Most of the people came to the garden.

(10) Most people came to the garden.

The people in (9) does not have to be specified; however, once of is used as in (10), the people must be part of a specific group to clearly indicate the larger whole to which a part belongs. With the use of of, most no longer refers to a large amount of people in an unspecific group; rather, it indicates a large amount of the whole. Therefore, people must be the people, a specific group denoted by the definite article.

\section{Differences Between Of and Other Prepositions}

$O f$, in essence, indicates the state of being a part of a larger whole. This is clear from a comparison of the functions of of with the functions of other prepositions. Additionally, the use of of must be compared with other prepositions, because a reason why learning prepositions challenges learners is that the differences among prepositions are not clear to them; as a result, confused by similarities, they often misuse prepositions. Before discussing how of is used in the authentic communication settings of films, some differences between of and other prepositions, namely, at, with, from, and in, are discussed.

Firstly, at is one of commonly misused prepositions, and it is mostly used in place of $o f$.

(11) I am a teacher at this school.

(12) I am a teacher of this school.

(Ishibashi et al., 1995, p. 819)

According to Ishibashi et al. (1995), (12) is grammatically incorrect, because the teacher is not a part of this school. The at in (11) represents a place where a teacher works. Interestingly, of can be used in the following sentences.

(13) Tom is the President of the United States of America.

(14) Tom is the Chair of Tokyo Junior High School. 
Examples (13) and (14) are grammatically correct since both the Chair and the President are parts of a larger whole. Evidently, a Chair and a President are positions within an organization; however, a teacher, like a worker, does not hold a real position in his or her organization. A teacher is an agent noun, and it means one who teaches; it is derived from the verb, to teach.

Secondly, as Leech and Svartvik (2002) explain, prepositions such as at, with, and of are typically used to describe or report emotive behavior.

(15) I was alarmed at his behavior.

(16) I was furious with him 1 .

(17) He was resentful of the successes of others.

(Leech \& Svartvik, 2002, p. 163)

Leech and Svartik (2002) suggest that $a t$ is used to express an emotive reaction to a thing, whereas with is used when a person or an object is the cause of an emotive reaction. However, the authors are silent on the use of of and the difference between the uses of the prepositions, especially in terms of expressing emotive reactions. Nonetheless, the subtle differences expressed in (17) are evident if one regards the essence of of as the state of being a part of a whole. The successes of others are parts of he, causing he to become resentful. Furthermore, being alarmed is an external reaction to something, as alarm can mean a call to arms and warning (Onions, 1966, p. 22), but being resentful is an emotion; it is internal. This, as can be seen, is similar to the difference between die of and die from.

(18) He died of cancer. (=(5))

(19) He died from the collision. (=(6))

At this juncture, it is important to analyze the common errors made by ESL learners.

(20) Japan met with defeat in the Pacific War, and Japanese people were forced to join the democratic countries in $\rightarrow$ of the world. $(=(1))$

(21) She accused the man for $\rightarrow$ of stealing. (=(2))

The errors in these sentences can be easily noticed if of is understood as that which denotes a state of being a part of a larger whole. Sentence (20) is not about the whereabouts

\footnotetext{
${ }^{1}$ The original sentences for (16) and (17) are I was furious with him for missing that penalty and As a former champion, he was annoyed about his own failures, and resentful of the success of others, respectively. In the examples, they appear in a slightly modified form to clarify the point at issue.
} 
of the democratic countries; rather, it expresses that they are parts of a larger whole, namely the world. Furthermore, (21) may be understood by many ESL learners as stating that the stealing was the reason for being accused. However, this reason could be either internal or external. If stealing is an external reason, detached from the man, there is no reason for she to accuse the man. She accused the man because of his stealing, his act; therefore, stealing is part of him, according to the accusation of she.

Additionally, there is one more crucial point concerning a part and the larger whole. In (22), the president is a part that belongs to the United States of America, the larger whole. In contrast, in (23), the upcoming event is a part of $I$, the larger whole.

(22) She is $(\underline{A})$ the president $o f_{(\mathrm{B})}$ the United States of America. $(=(13))$

(23) $)_{(\mathrm{A})} \underline{I}$ was informed of $f_{(\mathrm{B})}$ the upcoming event. $(=(3))$

Hence, in (22), A belongs to B (a part is followed by of). In (23), B belongs to A (a whole is followed by off). In other words, it is important to identify the part and the whole in a given sentence. A subject, a verb, and relations among words in a sentence are all keys to do so. It is necessary for learners to understand that of means the state of being part of a larger whole, and this represents the essence of of. To some extent, of is only a mark learners can use to locate a part and a whole.

As stated above, scholars have sought to list the main uses of of It is typically used to indicate such aspects as separation, materials, possession, themes, origin, affiliation, causes, etc. These uses are not meanings of of; rather they are meanings which typically manifest from the essence of of. Eto (2015) points out that of has two contradicting functions: affiliation and separation.

(24) I was informed of the upcoming event. (=(3))

(25) She was robbed of her watch. $(=(4))$

Affiliation and separation are not in fact functions of of. Instead, the meanings of these movements, affiliation, and separation, are natures of verbs used in (24) and (25). In other words, affiliation and separation are embedded in the verbs inform and rob, respectively. $O f$ does not mean affiliation or separation: it only indicates that a certain part is affiliated to a certain whole, or that a certain part is separated from a certain whole. A manifestation varies depending on the sentence, but the essence remains the same no matter what a given sentence means. After all, communication is the process of conveying a message that emerges from the relations between the words in a sentence. 


\section{VARIOUS USAGES OF OF IN COMMUNICATION SETTINGS}

\section{Using Film Dialog}

Film dialog, which can be authentic and meaningful, is suitable as texts for learners to concretely explore how grammar rules and principles work. Hirano (2014), focusing on understanding the essence of the English present perfect, gives an illustration of how to teach its grammatical function by using film dialog. Matsumoto (2014) also proposes a method of teaching phrasal verbs that depends on the use of the contextual knowledge that can be obtained in film dialog. Naturally, it follows that film dialog is as useful as illustration of subtle changes in preposition meanings. This section examines the use of of to express certain ideas, calling attention to the essence of of as indicating the state of being a part of a larger whole.

As noted, the method discussed here has two parts. First, learners come to understand the essence of a grammar item. The other is that learners explore the expression of this essence in authentic dialog. Once a teacher, for example, has ensured that the learners have grasped the essence of of, the teacher may ask them to characterize what nuances of may have in everyday conversations. Here are some intriguing uses of of in film dialog.

The following dialog has been taken from the television show Anne of Green Gables: The Sequel (Sullivan, 1987). Here Anne is bringing a piece of news to Brooke about two men who might become Brooke's boyfriend.

ANNE: You're so rosy and healthy. Your hair looks so attractive like that instead of all pulled back. Besides, I happen to know of two eligible young men who've asked about you.

BROOKE: Really?

(Conversation 2, Anne of Green Gables: The Sequel)

Anne says, I happen to know of two eligible young men, and the use of of here makes this subtly different from the simpler I happen to know two eligible young men. A similar example can be found in Charade (Donen, 1963).

INSPECTOR: We discovered your husband's body lying next to the tracks of the Paris-Bordeaux railroad line. He was dressed only in his pajamas. Do you know of any reason why he might have wanted to leave France? REGGIE: Leave? No... 
In this scene, the Inspector asks Reggie questions about her husband to solve the mystery surrounding his death. The Inspector asks, Do you know of any reason why he might have wanted to leave France? The preposition of could be omitted in both these cases, and grammatically speaking, its omission makes little difference; there is nonetheless a difference in what is communicated.

Here is another example taken from The Devil Wears Prada (Mckenna \& Frankel, 2006). Here Andrea is calling supposedly her superior, Emily, to ask a favor.

ANDREA: Hey, Emily, it's Andy. Don't hang up. I have a favor to ask you. EMILY: You have a favor to ask of me?

ANDREA: Yeah. The thing is, I have all these clothes from Paris, and I don't have any place to wear them.

(Conversation 4, The Devil Wears Prada)

Intriguingly, Andrea does not use of in her request. She simply says, I have a favor to ask you, but Emily does use of in her reply. Emily is in fact attempting to convey a certain message by using of. If learners can understand the essence of of as expressing a state of being a part a larger whole, teachers can encourage them to determine the meaning of of in this, as well as other dialog.

Teachers can also ask learners to identify the parts and wholes in the sentences.

(26) I happen to know of two eligible young men who've asked about you.

(27) Do you know of any reason why he might have wanted to leave France?

In both these sentences, know is the verb, and its respective objects are two eligible young men and any reason. A larger whole is knowledge itself; the of in (26) and (27) indicates that knowledge of two eligible young men and any reason is partial. In (26), Anne is indicating I happen to know two eligible young men, but I do not know them that well. The of in (26) expresses the second half. In (27), the inspector is attempting to convey, I believe it comes as a surprise to you, when he asks, Do you know any reason why he might have wanted to leave France? The of in his question conveys the first half. This can also be applied to understand the message Emily is trying to convey in (29).

(28) I have a favor to ask you.

(29) You have a favor to ask of me?

On the one hand, in (28), I and you are both wholes, and there are no parts that belong to either whole. In other words, $I$ and you are equal. On the other hand, in (29), you is a 
part of a larger whole, and me exists as a whole. In other words, me is bigger than you, and, to some extent, you belongs to me.

In (28), Andrea states, I have a favor to ask you, which indicates that she believes that the entirety of you is available for her to ask a favor, regarding $I$ and you as equal. Emily thinks otherwise. In (29), Emily seems to convey that you is only a part of me, and that me is not always available for you to ask a favor, emphasizing not only that you and me are not equal but that me is superior to you. In effect, by using of, Emily is really asking Andrea the following: Are you asking me a favor? Who do you think you are?

Next, let us consider the common expression, speaking of which. The verb, speak, can be followed by about or of, as in I speak about the tragedy and I speak of freedom. However, of cannot be replaced with about in the expression speaking of which. An example from The Dark Knight (Nolan, 2008) follows.

JOKER: That's okay. I came prepared. It's a funny world we live in.

Speaking of which, you know how I got these scars?

BATMAN: No, but I know how you got these.

(Conversation 5, The Dark Knight)

Learners are often unable to memorize a common phrase without, e.g., understanding why about cannot be used in the examples above. However, if teachers can help their learners grasp the essence of of, and if the leaners can develop a clear understanding of it, it might be possible for them to discover why of cannot be replaced with about here. Not only that, they might be able to transfer their understanding to other contexts. In this way, learners can build a better grammatical understanding while also enhancing their communication skills. Before the reason that of in speaking of which cannot be replaced with about is explained, here is another interesting use case of of.

MARILLA: Ah, Lord.

ANNE: Oh, what a worry my red hair used to be! Um, I'm afraid I've never been able to endure personal criticism very well. Gilbert gave his honest opinion of my story this afternoon. Why, my temper, it always gets the better of me!

(Conversation 6, Anne of Green Gables: The Sequel)

The noun opinion cannot be followed by about but must be followed by of; the reason for this is the same as the reason why speaking about which is ungrammatical. It relates, of course, to the essence of of, which denotes a part of a larger whole. 
In particular, opinion does not simply mean view or idea; rather, an opinion is something that one obtains only after careful consideration. An opinion cannot be about something because about means around, as in the phrase, Don't beat around/about the bush. The word about can never reach the core of things. For this reason, opinion and about are by their natures contradicting terms. Of, for its part, denotes a part of a larger whole. Gilbert gave his honest opinion of my story. If Gilbert gives an idea about Anne's story, this means that his idea is relatively vague, and he did not spend much time examining the story. The reason that Anne does not use the word idea here is that Anne believes that Gilbert carefully examined her story and constructed his views with honesty and diligence.

Speaking about which is ungrammatical because, again, about means around something. Speaking of which refers to a specific topic or theme that was mentioned immediately preceding the present moment. Therefore, which indicates something that everyone who is involved in the present conversation recognizes. In other words, whatever the topic is, it is part of shared knowledge.

The preposition of consists of only two letters, but it has several meanings, and its impact is far greater than learners anticipate. The complexity of this preposition cannot be understood by mere memorization. Grammar can be taught to enable learners to develop their communication abilities. Learners can be taught the essence of a particular rule; they can be encouraged to discover how the essence of a given rule is applied in different communication settings to express different meanings. In this way, learners can put their understanding to practical use. As Matsumoto (2014) suggests, learners tend to simply memorize the uses of prepositions, disregarding the fact they are crucial for effective communication. It is not surprising, then, that learners often treat know of and ask of as different idioms when they memorize them. Learners must be guided to discover the meanings of these idioms. If they are taught the essence of of, they may be able to guess, not memorize, the meanings of these idioms. Furthermore, film dialog is effective materials; they are like everyday conversations, or, at the very least, they are realistic and easily accessible conversations.

\section{The Difference Between Of Course and Sure Revisited}

Here, the subtle difference between of course and sure is explained as an example of the divorce that may occur between communication and grammar. Each expression is fairly easy for learners to use, but it is hard for them to understand the clear differences between them. Many teachers also have a hard time providing a simple explanation. Let us revisit the difference between of course and sure. 
MARCUS: You don't have a kid, do you?

WILL: Of course, I've got a kid. What are you talking about?

(Conversation 7, About A Boy)

If a student requests his or her teacher to explain the difference between these two words, the teacher may provide a systematic explanation, much like the ones found in textbooks. The teacher may ask the student to memorize certain principles, or he or she may suggest another route. For example, a teacher may guide learners to notice the of in of course. The teacher can then ask the students to identify the part and the larger whole in relation to of course.

In the scene given above, the part is represented by the statement I've got a kid, and the larger whole is course. Here, course could be considered to be something akin to destiny, something designed by a god or another higher power. By stating Of course, Will emphasizes that I've got a kid is a part of a course and cannot be doubted by anyone. Here, Will cannot reply, Sure. If he has a kid, he has a kid. He is not sure about having a kid. Simply put, the difference between of course and sure can be understood via such notions as subjectivity and objectivity. These are short versions of the sentences It is of course and I am sure. Of course is used to express that there is no room for judgment. The thing has been decided. It is the way it is, and everyone must agree with it. By contrast, sure indicates a strong sense of objectivity. It is $I$ who is telling you that things are the way they are.

If we were to substitute of course, for sure in the context below, the scene would ring false. In this scene, the film's antagonist Joker is threatening a woman with a gun, and the protagonist Batman is trying to save her.

JOKER: A little fight in you. I like that.

BATMAN: Then you're gonna love me. Drop the gun.

JOKER: Oh, sure. You just take off your little mask and show us all who you really are.

BATMAN: Let her go.

JOKER: Very poor choice of words...

(Conversation 8, The Dark Knight)

Joker cannot reply $\mathrm{Oh}$, of course instead of $\mathrm{Oh}$, sure because that dropping the gun as requested is not destined or already decided: instead, it remains within Joker's choice. Thus, of course does not fit. If Joker were to say, Oh, of course, it would mean that Joker agrees that his holding the gun is inappropriate, and furthermore, everyone, including a god, believes this. Joker clearly does not think in this way, as seen in the fact that his actions undercut this idea. If he were to reply Oh, of course, it would mean that Joker 
himself thought his actions were evil and was on the cusp of reforming. However, after saying, Oh, sure, Joker gives the condition that must be met. Joker will happily drop his gun, but Batman must reveal his identity.

The difference between of course and sure is a specific case. If learners understand the generalized meaning of of, namely its essence, then, they only must apply the essence in the specific case. By doing so, they can identify the part(s) and the whole. Doing so also throws light on the difference between of course and sure. A sentence consists of several words, and they are organized according to more than one grammatical rule. Teachers may try to explain these rules by listing all the main uses of prepositions, just as many textbooks do. However, in this method, learners may not be able to see how the rules are related to one another.

\section{CONCLUSION}

The study of grammar should not be mostly full of painful memorization: rather, it should be constructive, effective, and interesting. However, this issue has been largely ignored, and teachers must depend on unimproved, orthodox, and mechanistic grammar instruction methods that have not kept pace with research. As a result, students are required to refer to materials that are organized systematically and to commit all grammatical rules and principles to memory. It is clear that this method cannot help learners fully understand grammar rules or develop their communication abilities. To accomplish this, a sound knowledge of grammatical rules must serve as a firm foundation to linguistic understanding and expression. Once students develop a sound basis in grammar, teachers can then more easily guide them through examples and actual communicative settings.

Additionally, teachers must also discuss the implications of their teaching methods to enable learners to explore how the essence is applied in actual communication settings, as well as how it takes on various meanings. Using film dialog is just one way of enabling learners to understand how grammatical rules are applied in actual communication settings. By examining the inherently nuanced nature of actual communication settings, learners can improve their understanding of grammar, as well as their communication abilities.

The paper proposes a new method of teaching grammar that focuses on the essence of a grammar rule, using film dialog as learning material. The most fundamental meaning of of is to be part of a larger whole. Learners are not required to go pass through systematically organized materials and memorize all the functions of each preposition. Instead, they can learn the fundamental meaning for grammatical elements such as the preposition of as the smallest yet strongest foundation for learners to brush up on their communication skills and abilities. 
It should be noted that the authors do not assert that this is the only way to teach grammar; rather, this is one possible way among many. As Al-Mekhlafi and Nagaratnam (2011) note, "There may be generally recommended ways of teaching EFL grammar..., but it would not be proper to adopt them universally without looking at the possible difficulties that might go with those methods suggested" (p. 82). There are many grammar rules, language elements, and linguistic principles that are equally difficult to understand. The use of film dialog may not be the best means to illustrate or develop some grammar rules. Further detailed research must be undertaken to improve methodologies of grammar instruction. The one thing to remember while doing so is that grammar and communication are by no means oil and water: they are the inseparable ingredients of English competency.

\section{REFERENCES}

Al-Mekhlafi, A. M., \& Nagaratnam, R. P. (2011). Difficulties in teaching and learning grammar in an EFL context. International Journal of Instruction, 4(2), 69-92.

Ban, H., \& Minagawa, J. (2013). Nintendo DS-wo mochiita daigakusei-no eigogakushuunikansuru ichikousatsu [A consideration on English learning for undergraduates using Nintendo DS]. The Reports of IEICE. ET, 113(229), 105-108.

Donen, S. (Producer/Director). (1963). Charade [Motion picture]. United States: Universal Pictures.

Egawa, T. (1981). Eibunpou kaisetsu [A new guide to English grammar]. Tokyo: Kaneko Shobou.

Eto, Y. (2015). Eibunpou-no essence [The essence of English grammar]. Tokyo: Taishukan.

Fujimori, A., \& Yoshimura, N. (Eds.). (2013). Animation-wo mochiita zenchishi shidou: houkou zenchishi-wo rei-toshite [Animated instructions for directional prepositions: Theoretical studies and experimental studies]. CELES Journal, 42, 77-82.

Fuyuno, M. (2013). Rote learning in English education for Japanese students: Towards more context-oriented multimedia material. The Journal of Design, 20, 1-8.

Gitsaki, G. (2005). Course design to promote student autonomy and lifelong learning skills: A Japanese example? In H. Anderson, M. Hobbs, J. Jones-Parry, S. Logan, \& S. Lotovale, Supporting independent learning in the 21st century: Proceedings of the Independent Learning Association Conference Inaugural (pp. 1-10). Auckland: Independent Learning Association Oceania.

Greenbaum, S., \& Quirk, R. (1990). A student's grammar of the English language. Harlow, Essex: Longman.

Hirano, J. (2014). Analysis on rhetorical aspects on the present perfect: Searching for the 
effective grammar instruction. ATEM Journal, 19, 73-87.

Horiike, Y. (2003). Corpus-wo riyou sita eigo-no kudoushi-no kenkyuu: dougi-to sareru tanitsudousi to hikakushite [A study on English phrasal verbs using corpus: Comparing with verbs which seem to have the same meaning]. Studies in Linguistic Expression, 19, 1-11.

Howell, P. (2014). Using manga in teaching English as a foreign language. Hiroshima Gaikokugo Kyouiku Kennkyuu, 17, 195-204.

Ishibashi, K., Hirose, T., Ito, K., Takanashi, K., Torii, T., \& Watanabe, T. (1995). Eigogoho daijiten 4 [A dictionary of current English usage-4]. Tokyo: Taisyukansyoten.

Kamimoto, T. (2006). How university students' grammatical knowledge has changed over ten years. The Bulletin of Kumamoto Gakuen University, 13(2), 1-29.

Kimura, K., \& Wakasugi, S. (2014). Korekara-no eigokyoiku-nikansuru kosatsu: Global English-no sonzai-wo fumaete [The study on English education in the future: Considering global English]. Japan Society of Educational Information Annual Proceedings, 30, 142-143.

Kondo, K. (1984). Eigo zenchishi koubun-no kigen [The origin of English preposition construction]. Tokyo: Shohakusha.

Kotani, Y. (2003). Eigokudoushi niokeru gakushuuzyou-no mondai-wo saguru [Discussing problems of learning English phrasal verbs]. Bulletin of Tokyo Denki University, Arts and Sciences, 1, 35-42.

Leech, G., \& Svartvik, J. (Eds.). (2002). A communicative grammar of English. Harlow: Pearson Education.

Leki, I. (1996). L2 composing: Strategies and perceptions. In Leeds, B. (Ed.), Writing in a second language: Insights from first and second language teaching and research (pp. 27-36). London: Longman.

Li, D. (2001). Teachers' perceived difficulties in introducing the communicative approach in South Korea. In D. R. Hall \& A. Hewings. (Eds.), Innovation in English language teaching: A reader (pp. 149-166). New York, NY: Routledge.

Lorincz, K., \& Gordon, R. (2012). Difficulties in learning prepositions and possible solutions. Linguistic Portfolios, 14(1), 1-5.

Matsumoto, T. (2014). One method of teaching English phrasal verbs using movies. ATEM Journal, 19, 121-135.

Matsushita, E. (2012). Nihonjingakushuusya-no Zenchishisiyoukeikou: Gakushuusha Copus-no Keiryoutekibunseki (Shikou-to Gengo) [Tendency of using prepositions by Japanese learners: A statistical analysis based on learner corpus]. The Report of the Institute of Electronics, Information and Communication Engineer, 112, 47-52.

McKenna, A. B. (Writer), \& Frankel, D. (Director). (2006). The devil wears prada [Motion picture]. United States: 20th Century Fox. 
Mochizuki, K., Koga, K., Sano, H., Kano, K., \& Okuma, Y. (2013). Incorrect use of prepositions in an online error corpus of written English by advanced learners compiled by Tokyo university of foreign studies (Collaboration and relativization in English language education). The JACET Annual Convention, 52, 111-112. http://dl.ndl.go.jp/info:ndljp/pid/10499341

Murasato, Y., \& Orita, M. (2008). Eibunpo-eno jishindo rikaido oyobi eigojukutatsudo-ni taisuru gakushushatokusei-no setsumeiryoku [Learner traits as determinants of L2 grammatical confidence, competence, and overall L2 Proficiency]. Studies in English Language and Literature, 51, 55-80.

Nakahara, K., \& Nakagawa, N. (2010). Communication-zyushi-no eigokyouikunitaisurufurikaeshi-to eigokyouiku-no arubeki sugata [Reflection on communication-centered English education and an appropriate image of English education]. Quarterly Journal of the Economic Research Institute of Kanto Gakuin University, 245, 119-135.

Nakata, Y. (1999). Gengogakusyuu motivation: Riron to jissenn [Language learning motivation: Theories and practice]. Liber: Tokyo.

Nakata, Y. (2006). Motivation and experience in foreign language learning. Oxford: Peter Lang.

Nation, I. S. P. (2001). Learning vocabulary in another language. Cambridge, UK: Cambridge University Press.

Nekoda, H. (2015). Communication-wo sasaeru bunpouryoku-no ikusei: Processing Instruction (PI)-ni shouten-wo atete [Teaching grammar for communication: focusing on processing instruction]. Memoirs of the Faculty of Education, Shimane University. Educational Science, Literature and Social Science, Natural Science, 48, 31-40.

Nolan, C. (Producer/Director). (2008). The dark knight [Motion picture]. United States: Warner Brothers.

Of course. (n.d.). In Longman dictionary of contemporary English (6th ed.). Retrieved from https://www.ldoceonline.com/

Onishi, H., \& McVay, P. C. (2006). Heart de kanjiru eibunpou [English grammar you feel by heart]. Tokyo: NHK Press.

Onishi, H. (2014). Bunposhido-no kandokoro [Points of grammar teaching]. The English Teachers'Magazine, 63(9), 10-12.

Onions, C. T. (1966). The Oxford dictionary of English etymology. Oxford: The Clarendon Press.

Online dictionary of misused English. (n.d.). Retrieved from http://sano.tufs.ac.jp/lcshare/

Oxford advanced learner's dictionary of current English (9th ed.). (2015). London: Oxford University Press. 
Petersen, M. (2014). Nihonjin-no eigo-wa naze machigaunoka? [Why do Japanese people make mistakes in English?]. Tokyo: Shueisha.

Rosenthal, J., De Niro, R., Epstein, B., Bevan, T., \& Fellner, E. (Producers), \& Weitz, C., \& Weitz, P. (Director). (2002). About a boy [Motion picture]. United Kingdom, United States, France \& Germany: Universal Pictures.

Seki, A. (2008). Jiritsuteki-ni eigogakusyuu-o susumeruchikara-o ikuseisurusidou: Tanndai-deno jissennrei [Education to foster autonomous English learning: Reports on practice at a junior college]. The English Teachers' Magazine, 56(2), 17-19.

Shirono, H. (2014). Communication noryoku-o nobasu bunposhido-ga dookiduke-ni ataeru eikyo [The Influence of Communication Oriented Grammar Instruction on Motivation]. CELES Journal, 43, 73-80.

Silsbee, S. (2016). Kyoudou kenkyu CALL-to tadoku puroguramu-niokeru eigo nouryoku-no kouzyou-no hyouka [EFL Students' Perceptions on the Use of Online Fantasy Sports]. St. Andrew's University Bulletin of the Research Institute, 42(1), 143-166.

Sullivan, K. (Writer/Director). (1987). Anne of Green Gables: The sequel [Motion picture]. Canada: Anne of Green Gables Productions et al.

Sure. (n.d.-a). In Cambridge academic content dictionary (1st ed.). Retrieved from https://dictionary.cambridge.org/

Sure. (n.d.-b). In Collins English dictionary (12th ed.). Retrieved from https://www.collinsdictionary.com/dictionary/english

Swan, M. (2016). Practical English usage. New York, NY: Oxford University Press.

Takeoka, H. (2010). Takeokashiki mou mayowanai zenchishi [Takeoka's effective way of learning prepositions]. Tokyo: Asahi Shinbun Syuppan.

Tanaka, S., Sato, Y., \& Abe, H. (2006). Eigo kankaku ga mi ni tsuku jissenteki shidou [Practical instruction to acquire English senses]. Tokyo: Taishukan.

Ueda, M. (2011). Research on demotivation in English learners and learner autonomy needs analysis from the viewpoint of remedial education (Project/Area No. 20520529). The Report on Research Achievements for Grants-in-Aid for Scientific Research. Tokyo, Japan: Japan Society for the Promotion of Science.

Watanuki, Y., \& Petersen, M. (2006). Hyougen-no tame-no jissen royal eibunpou [The royal English grammar for practical expressiveness]. Tokyo: Obunsha.

Zhen, C., \& Park, J. (2003). An analysis of errors in English writing made by Chinese and Korean university students. Theory and Practice in Language Studies, 8(3), 13421351. 
Applicable level: university

Keywords: communication, grammar teaching, of, essence, film dialog

Hirano, Junya (First author)

Kumamoto University

2-40-1 Kurokami, Kumamoto, Kumamoto, Japan 860-8555

E-mail: jh97t@kumamoto-u.ac.jp

Matsumoto, Tomoko (Second author)

Nagasaki International University

2825-7 Huis Ten Bosch Machi, Sasebo, Nagasaki, Japan 859-3298

E-mail: tmatsumoto@niu.ac.jp

Received: March 31, 2018

Revised version: May 16, 2018

Accepted: May 26, 2018 